\title{
Early and Advanced Glycosylation End Products Kinetics of Formation and Clearance in Peritoneal Dialysis
}

\author{
Miriam A. Friedlander, Yu Ching Wu, Abdelhamid Elgawish, and Vincent M. Monnier \\ Department of Medicine and Institute of Pathology, Case-Western Reserve University, Cleveland, Ohio 44106
}

\begin{abstract}
The chronic contact of glucose-containing dialysate and proteins results in the deposition of advanced glycation end products (AGEs) on peritoneal tissues in patients treated by peritoneal dialysis (PD), yet plasma levels of the AGE pentosidine are significantly lower in PD than in hemodialysis (HD). We measured glycation of peritoneal proteins in patients on PD over the time course of intraperitoneal equilibration of fresh peritoneal dialysate. The glycated content of peritoneal proteins (furosine method) was initially identical to plasma but increased $200 \%$ within $4 \mathrm{~h}$ due to in situ glycation as also demonstrated in vitro. In contrast, peritoneal proteins contained a 2-4 $\times$ greater content of the AGE pentosidine at all equilibration time points. Plasma protein furosine content was identical in patients on PD and on HD. Fractionation by gel filtration of serum from patients on PD and $\mathrm{HD}$ revealed that $>95 \%$ of the pentosidine was linked to proteins $>10,000 \mathrm{~mol} \mathrm{wt} ;<1 \%$ to proteins $<10,000 \mathrm{~mol}$ wt; and $<1 \%$, free. Neither HD nor PD affected proteinbound pentosidine. The HD treatment decreased free and $<10,000 \mathrm{~mol}$ wt bound pentosidine. However clearance of protein-associated pentosidine by the peritoneal membrane may explain lower steady state levels in patients treated by PD. (J. Clin. Invest. 1996. 97:728-735.) Key words: pentosidine $\bullet$ furosine $\cdot$ hemodialysis $\bullet$ peritoneal dialysis $\bullet$ peritoneal transport
\end{abstract}

\section{Introduction}

The Maillard reaction is ubiquitous in nature. Glucose reacts nonenzymatically with primary amino groups on proteins to form glycated residues, called Amadori products. Amadori products undergo a series of dehydration and fragmentation reactions to form the stable covalent adducts called advanced glycation end products (AGEs). ${ }^{1}$ Recently, the accumulation of AGEs in tissues in the human body has been implicated in the complications of diabetes, aging, and renal failure $(1,2)$. In

Address correspondence to Miriam A. Friedlander, Department of Medicine, Case-Western Reserve University School of Medicine, 2109 Adelbert Road, Cleveland, OH 44106. Phone: 216-844-8272; FAX: 216-368-5824.

Received for publication 18 November 1994 and accepted in revised form 16 November 1995.

1. Abbreviations used in this paper: AGE, advanced glycation end products; D/P, dialysate/plasma ratio; HD, hemodialysis; MTAC, peritoneal mass transfer area coefficient; PD, peritoneal dialysis.

J. Clin. Invest.

(C) The American Society for Clinical Investigation, Inc. 0021-9738/96/02/0728/08 \$2.00

Volume 97, Number 3, February 1996, 728-735 this study we used the chemically defined AGE pentosidine (a lysine-arginine cross-link formed during glycoxidation of Amadori products) as a marker of the advanced glycation reaction. The pentosidine content of collagen-rich tissues has been demonstrated to increase with age (1). Both skin and plasma content is further increased in the presence of diabetes, where levels are found to correlate with severity of complications (3-5). The highest levels of pentosidine are found on tissue and circulating proteins from patients with renal failure $(1,6,7)$.

Peritoneal dialysis (PD) differs from hemodialysis (HD) in that the patient's peritoneum, not an artificial kidney, forms the dialyzing membrane. Commercially available PD solutions contain supraphysiologic concentrations of glucose. The chronic contact of glucose-containing dialysate and proteins results in glycation of peritoneal tissues in patients treated by PD (7). We hypothesized that peritoneal dialysis would result in accelerated formation of early and advanced glycation end products, due to the in vivo incubation of peritoneal proteins and dialysate glucose. To test this hypothesis we measured Amadori products (early glycation) by performing acid hydrolysis of peritoneal and plasma proteins in order to measure the stable product furosine (8). We used both in vivo and in vitro kinetic modeling to gauge the impact of high peritoneal glucose concentrations on the formation and clearance of Amadori and AGE products on peritoneal proteins. Paradoxically, plasma protein levels of the AGE pentosidine are significantly lower in patients treated by PD than HD (7). Therefore, we also compared the effectiveness of PD and HD on the clearance from serum of glycated fractions of serum proteins separated by gel filtration.

\section{Methods}

\section{Study patients}

Peritoneal equilibration testing was performed as part of routine care in 28 patients with end stage renal failure treated by PD. In accordance with guidelines provided by the Institutional Review Board of University Hospitals of Cleveland, verbal consent was obtained to process dialysate and plasma samples for research as well as routine testing. Blood was obtained for plasma furosine and pentosidine levels with the consent of an additional 21 patients before the HD treatment, and an additional 10 patients before performing the morning PD exchange. Blood was also obtained both before and after (at $3 \mathrm{~h}$ ) a HD treatment or PD exchange in a third group of 6 patients treated by HD and 6 treated by PD. There were no statistical differences in the composition of these groups of study patients with regard to race, sex, or prior history of diabetes. The PD patients had a mean age of 51.4 yr (range 25-82); HD, 55.1 (range 22-83). Among the patients treated by peritoneal dialysis there were 18 males and 26 females. 9 males and 19 females underwent kinetics testing. The patients treated by HD included 12 males and 15 females. The PD group included 24 African Americans, 19 Caucasians, and 1 Oriental, compared to 21 African Americans and 6 Caucasians in the HD group. Diabetic subjects comprised $39 \%$ of the PD and $44 \%$ of the HD group. All HD patients received routine treatment with polysulfone hollow-fiber di- 
alysis filters (F8 or F80; Fresenius USA, Concord, CA) and bicarbonate buffer dialysate. Dialyzers are re-used after reprocessing on a Renatron II system from Renal Systems (Minneapolis, MN) using Renalin $^{\circledR}$. The peritoneal equilibration tests were performed within 1 mo of initiation of peritoneal dialysis in 20 of the patients. No differences were found in peritoneal equilibration test results between these subjects and the 8 individuals in whom tests were performed after 6-18 mo of PD. To determine the peritoneal fluid protein content of pentosidine and furosine in individuals with normal renal function, peritoneal fluid was obtained by aspiration at the time of laparoscopy in healthy women undergoing elective laparoscopic tubal ligation. All laparoscopy subjects provided signed informed consent, and also allowed the collection of blood for the determination of plasma levels of pentosidine and furosine. The subjects consisted of 9 women, with a mean age of $38.8 \mathrm{yr}$ (range 22-59); 5 were of African-American and 4 of Caucasian origin.

\section{In vitro and in vivo kinetics}

In vitro kinetics studies were performed by incubating known quantities of protein from three sources with commercial dialysate (Dianeal ${ }^{\circledR}, 2.5 \%$ glucose; Baxter Corp., McGaw Park, IL) or a solution of $2.5 \%$ glucose in water for various time periods. The sources of the protein were whole serum from a healthy individual, spent peritoneal dialysate pooled from the drained overnight dwells of 20 patients on PD, and HSA purchased from Sigma Chemical Co., St Louis, MO. At the end of each incubation time period, the samples were applied to a 3,000 mol wt Centricon size-selective filter purchased from Amicon, Inc., Beverly, MA and centrifuged at 7,000 rpm, $4^{\circ} \mathrm{C}$ for $120-240 \mathrm{~min}$. The low molecular weight fraction (containing glucose) was discarded, and the high molecular weight fraction (containing protein) frozen at $-80^{\circ} \mathrm{C}$ until assay.

Dialysate samples were obtained from the overnight dialysate bag ( $~ 10 \mathrm{~h}$ of incubation, also called "pretest"), at time 0 immediately after an exchange with Dianeal ${ }^{\circledR}(2.5 \%$ glucose $)$, and at 2 and $4 \mathrm{~h}$ of dwell time. A 5-ml sample of whole blood in EDTA was obtained at the midpoint of the peritoneal equilibration test. Dialysate samples were placed on ice for transport to the laboratory. Within 10-15 min of withdrawal from the peritoneum, each sample was applied to a 3,000 mol wt Centricon size-selective filter and processed as described for in vitro kinetics above.

\section{Free pentosidine}

We measured free pentosidine levels in plasma obtained before and after hemodialysis (at $3 \mathrm{~h}$ ) in six patients treated with polysulfone hollow-fiber dialyzers (F80). For comparison we obtained serum from six patients before and at $3 \mathrm{~h}$ after a peritoneal dialysis exchange. We also examined the free pentosidine content of serum and peritoneal dialysate from the peritoneal equilibration tests of 6 of the 28 patients.

The processing of plasma and dialysate in order to measure "free" non-protein bound pentosidine was modified from the methods of Takahashi $(9,10)$. Plasma $(0.5 \mathrm{ml})$ was subjected to precipitation with an equal volume of $100 \mathrm{~g} /$ liter perchloric acid on ice followed by centrifugation at $1,000 \mathrm{~g}$ for $15 \mathrm{~min}$. The supernatant of the plasma precipitation procedure or an aliquot of peritoneal dialysate $(0.125 \mathrm{ml})$ was added to $15 \mathrm{ml}$ of water and applied to a tC18 SepPak column from Waters Division of Millipore, Marlborough, MA. The $15 \mathrm{ml}$ volume passed through the column was then dried under a vacuum and resuspended in $300 \mu \mathrm{l}$ of $0.01 \mathrm{M}$ heptafluorobutyric acid purchased from Sigma Chemical Co. for injection onto the HPLC as described below. Free plasma or peritoneal dialysate pentosidine was expressed per milliliter of initial sample volume.

\section{Gel filtration fractions of serum and dialysate}

Serum was obtained before and after dialysis (at $3 \mathrm{~h}$ for patients treated by HD, or $3 \mathrm{~h}$ after an exchange in patients on PD). Spent dialysate was obtained from the discarded overnight drain bags of 20 patients and combined to form a pool. $250 \mu \mathrm{l}$ of whole serum from two patients, both without diabetes, one treated by PD and the other by $\mathrm{HD}$ or $1 \mathrm{ml}$ of the pooled peritoneal dialysate was applied to a Bio-gel P30 column (Bio-Rad Laboratories, Melville, NY) $(50 \times 1.5$ $\mathrm{cm}$; fraction size $3 \mathrm{ml}$, flow rate $0.296 \mathrm{ml} / \mathrm{min}$, using a solvent composed of $0.05 \mathrm{M}$ Hepes from Bio-Whittaker [Walkersville, MD] and $0.15 \mathrm{M} \mathrm{NaCl}, \mathrm{pH}$ 7.4). Optical density was measured by spectrophotometer at $280 \mathrm{~nm}$. The fractions were calibrated using mol wt standards (thyroglobulin 670k, $\gamma$-globulin $158 \mathrm{k}$, ovalbumin $44 \mathrm{k}$, myoglobin $17 \mathrm{k}$, and insulin 5.8k) obtained from Bio-Rad. Fluorescence was measured in each fraction with an excitation of $335 \mathrm{~nm}$, emission 385 $\mathrm{nm}$. Based on the OD signal, 5-8 fractions of the serum or pooled dialysate were combined. Pentosidine was measured as described below, and expressed as pmol per $3 \mathrm{ml}$ fraction.

Serum, obtained both before and after dialysis, and a sample of pooled spent peritoneal dialysate was applied to a $10,000 \mathrm{~mol}$ wt Centricon size-selective filter and centrifuged at $7,000 \mathrm{rpm}, 4^{\circ} \mathrm{C}$ for 120 $240 \mathrm{~min} .200 \mu \mathrm{l}$ of the low molecular weight fractions from six serum samples obtained from patients on HD before treatment, HD after treatment ( $3 \mathrm{~h})$, PD before exchange, and PD at $3 \mathrm{~h}$ after exchange were combined to form four samples of $1.2 \mathrm{ml}$ each. Each combined sample and $1.2 \mathrm{ml}$ of the $<10,000 \mathrm{~mol} \mathrm{wt}$ fraction of the pooled peritoneal dialysate was applied to a Bio-gel P6 column $(45 \times 1.5 \mathrm{~cm}$; fraction size $3 \mathrm{ml}$, flow rate $0.25 \mathrm{ml} / \mathrm{min}$ ). Mol wt standards applied to the P6 column included myoglobin (17k), insulin (5,807.6 mol wt), and vitamin B12 $(1,355 \mathrm{~mol} / \mathrm{wt})$. The fraction containing free pentosidine standard ( $379 \mathrm{~mol} \mathrm{wt})$ was identified as a fluorescence peak. Fluorescence and OD were measured as above. The protein in each fraction was precipitated and acid hydrolyzed. Pentosidine was measured as described below, results expressed as pmol per $3 \mathrm{ml}$ fraction.

\section{Assay procedures}

Plasma and dialysate total protein was assayed in a microassay modification of the Bradford method using Coomassie brilliant blue G250 obtained from Bio-Rad Laboratories, Melville, NY. Plasma dialysate glucose was measured by the clinical laboratory at University Hospitals of Cleveland using an autoanalyzer method. $\beta-2$ microglobulin was measured in a commercial ELISA purchased from Kabi Pharmacia Diagnostics, Piscataway, NJ.

HPLC method for pentosidine. Pentosidine was measured using a modification of the method of Odetti et al. (11). Plasma or dialysate protein was subjected to acid hydrolysis. Protein was precipitated on ice with $10 \%$ TCA from Fisher Scientific Co., Pittsburgh, PA. The pellets were washed twice with $5 \%$ cold TCA and acid hydrolyzed in $1 \mathrm{ml} 6 \mathrm{~N} \mathrm{HCl}$ for $16 \mathrm{~h}$ at $110^{\circ} \mathrm{C}$ in borosilicate tubes with Teflon coated screw caps. Acid was removed by vacuum centrifugation, Savant Instruments Inc., Farmington, NY. The hydrolyzed pellet was dissolved in $250 \mu$ l of water/0.01 M heptafluorobutyric acid purchased from Sigma Chemical Co. The hydrolysate was filtered with $0.45-\mu \mathrm{m}$ nylon microfilterfuge tube obtained from Rainin Instrument Co., Woburn, MA. The equivalent of $0.8 \mathrm{mg}$ of plasma protein was injected onto an HPLC system, Waters Division of Millipore. The column used was a $25 \times 0.46 \mathrm{~cm} \mathrm{C}-18$ Vydac type $218 \mathrm{TP}(10 \mu \mathrm{m})$ column purchased from Separations Group, Hesperia, CA. The HPLC was programmed with a linear gradient from 0 to $35 \mathrm{~min}$ of $10-17 \%$ acetonitrile (chromatography grade obtained from Fisher Scientific Co.) in HPLC water and $0.1 \%$ heptafluorobutyric acid as a counter ion. Pentosidine eluted at $\sim 30 \mathrm{~min}$ as monitored by fluorescence excitation at $335 \mathrm{~nm}$ and emission at $385 \mathrm{~nm}$. Pentosidine prepared according to published procedure was used as a standard (3). Results were calculated per milligram added protein or milligram collagen protein. The intraassay coefficient of variation for a pentosidine standard of 15 pmol was $8.6 \%$ (Mean 14.98 \pm .09 ). The interassay coefficient of variation for a pooled sample of spent peritoneal dialysate processed and assayed in each of nine assays was 15.9 (mean $36.81 \pm 5.84 \mathrm{pg} / \mathrm{mg}$ protein).

HPLC method for furosine. Protein $(0.25 \mathrm{mg})$ from plasma and dialysate was processed as described above. The hydrolyzed protein pellet was resuspended with $400 \mu 10.4 \%$ acetic acid. The equivalent 
of $125 \mu \mathrm{g}$ of filtered hydrolysate was injected onto the HPLC system. The chromatographic conditions were modified from the method of Resmini et al. (12), as described by Wu et al. (8). Before column analysis, the injected sample was filtered with a Guard-Pak in line filter obtained from Waters Division of Millipore. The column used was a furosine-dedicated C8 column $(250 \times 4.6 \mathrm{~mm})$ obtained from Alltech Inc., Milan, Italy. The solvents used were $0.4 \%$ acetic acid (solvent A) and $0.27 \%$ potassium chloride dissolved in solvent A (solvent B). The elution gradient was expressed as the proportion of solvent B: 0-12.5 min, $0 \%$; $12.5-22 \mathrm{~min}, 50 \%$; 22-32 min, $0 \%$. The flow rate was $1.2 \mathrm{ml} /$ min. Furosine elutes at $29 \mathrm{~min}$ as monitored by an LC Spectrophotometer 481 UV detector (Waters Division of Millipore) set at 280 $\mathrm{nm}, 0.01$ AUFS. The interassay coefficient of variation for a pooled sample of spent peritoneal dialysate processed and assayed in each of three assays was 0.144 (mean $1196 \pm 172 \mathrm{pg} / \mathrm{mg}$ protein).

\section{Calculations and statistics}

Peritoneal mass transfer area coefficient (MTAC) was calculated for urea, creatinine, $\beta-2$ microglobulin, total protein, free pentosidine, and furosine using the following equation (13):

MTAC $=-(4 \mathrm{~h}$ drain volume $/ 240 \mathrm{~min}) \times \log _{\mathrm{e}}(1-4 \mathrm{~h} D / P)$

All data are expressed as mean \pm SD. Comparisons between time points in the peritoneal equilibration tests were made by ANOVA. A $P$ value of $<0.05$ was considered statistically significant. $D / P$ stands for dialysate/plasma ratio.

\section{Results}

Fig. 1 shows the results of the standard peritoneal equilibration test for total protein, $\beta-2$ microglobulin, and glucose, in the 28 subjects. The typical pattern of the loss of the glucose osmotic gradient with time is contrasted with the increasing concentration of intraperitoneal total protein and $\beta-2$ microglobulin. The in vitro kinetic model using $2.5 \%$ Dianeal ${ }^{\mathbb{R}}$ differs from our in vivo model in that intraperitoneal buffers rapidly balance the initial low $\mathrm{pH}$ of 5.4 at time 0 to $\mathrm{pH} 7.5$ at 30 min (data not shown). The $\mathrm{pH}$ remains constant at 7.4-7.6 throughout the remainder of the peritoneal equilibration test. Fig. 1 also demonstrates the changing relationships of concentrations of glucose and protein throughout the time period of peritoneal equilibration. From a kinetic viewpoint, it is important to realize that the time 0 glucose concentration is $>140$ $\mathrm{mM}$ which is 25 times higher than physiological concentrations. The concentration of glucose falls throughout the intra-

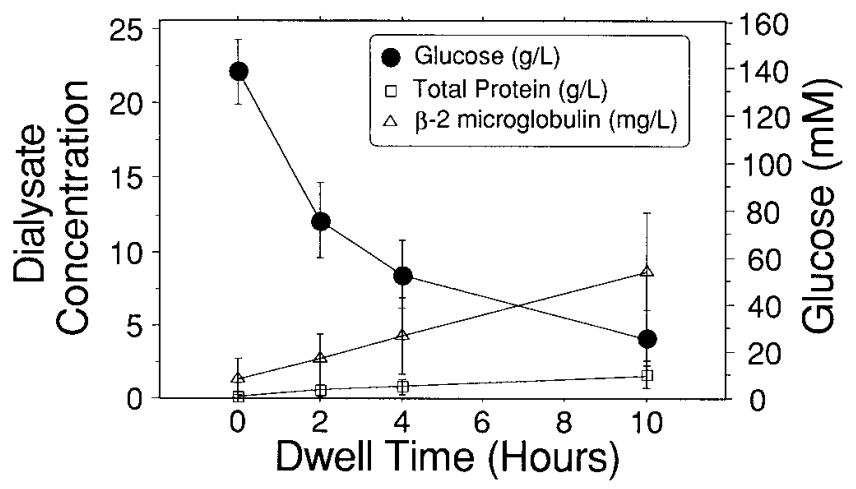

Figure 1. Peritoneal equilibration test. Changes in dialysate glucose $(\bullet)$, total protein $(\square)$, and $\beta$-2 microglobulin levels $(\triangle)$ during peritoneal equilibration testing in 28 patients on peritoneal dialysis. The figure contrasts the relative concentrations of glucose and protein in the peritoneum during the period of observation. peritoneal dwell period but is still $50 \mathrm{mM} 4 \mathrm{~h}$ later. The glucose concentration of the commercial dialysate before infusion into the peritoneum was $2,456 \pm 127 \mathrm{mg} / 100 \mathrm{ml}$. From Fig. 1, one can estimate that the average peritoneal glucose concentration is $\sim 30 \mathrm{mM}$. Thus the peritoneum is in a constant state of marked hyperglycemia.

Evidence for the presence of an intraperitoneal state similar to diabetes is apparent from the glycation data in the top of Fig. 2. In nondiabetic patients (open bars), the content of protein which is glycated (measured as furosine) at time 0 is not different from plasma, suggesting that less completely glycated plasma proteins move across the peritoneal membrane in response to the infusion of fresh hypertonic dialysate. A rapid increase in glycation $(P<0.003)$ by $66 \%$ occurs within $2 \mathrm{~h}$ followed by a $200 \%$ peak at $4 \mathrm{~h}(P<0.0001)$. Although higher than plasma $(P<0.04)$, the furosine content of the 10 -h sample is significantly lower than the $4 \mathrm{~h}$ peak $(P<0.05)$, suggesting either equilibration with plasma glycated proteins or fur-
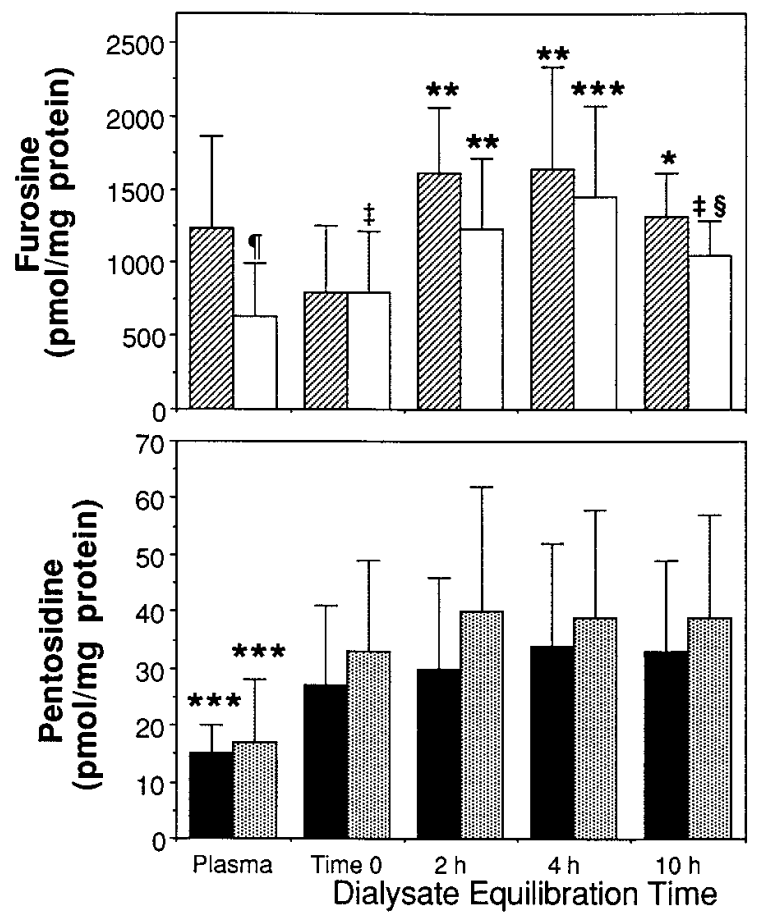

Figure 2. Kinetics of formation and clearance of glycated proteins during peritoneal equilibration test. Top: Furosine content of protein from the peritoneal equilibration tests of 20 peritoneal dialysis patients. Striped bars represent diabetics $(n=10)$ and open bars represent patients without diabetes $(n=10)$. Comparisons made within groups (diabetic or nondiabetic): $* P<0.05$, $* * P<0.005$, *** $P<$ 0.0001 for differences in furosine content of dialysate proteins at times indicated compared to furosine content of dialysate proteins at time $0 .{ }^{\ddagger} P<0.05$ comparing furosine content of peritoneal proteins at times indicated to plasma furosine levels for the same group. ${ }^{\S} P<$ 0.05 comparing furosine content of 10 -h peritoneal proteins with peak furosine content at $4 \mathrm{~h}$ of incubation. Comparisons made between groups: ${ }^{\mathbb{T}} P<0.05$ comparing plasma furosine levels in diabetic and nondiabetic patients on PD (Also see Fig. 4). Bottom: Pentosidine content of protein from the peritoneal equilibration tests of 28 peritoneal dialysis patients. Solid black bars represent diabetics $(n=12)$ and stippled bars represent patients without diabetes $(n=16)$. *** $P<0.0001$ comparing plasma pentosidine level to pentosidine content of dialysate protein at $2 \mathrm{~h}, 4 \mathrm{~h}$, and $10 \mathrm{~h}$. 
ther chemical reaction of the Amadori product on the pathway to forming advanced glycation products.

Patients with diabetes (hatched bars, top, Fig. 2) demonstrate a similar pattern of significantly increased glycation of peritoneal proteins at $2(P<0.001)$ and $4(P<0.001) \mathrm{h}$ of intraperitoneal incubation. However, the 10-h sample of dialysate protein, although lower than the $4 \mathrm{~h}$ peak, is not statistically different from the furosine content of plasma protein. In addition, the diabetic individuals have a significantly elevated furosine content of plasma proteins compared to nondiabetics $(P<0.05)$. Interestingly, the furosine content of plasma proteins from diabetic subjects is significantly greater than the furosine content of their peritoneal proteins at time $0(P<0.05)$, suggesting differences in the transport across the peritoneum of proteins altered by the Amadori rearrangement.

The peritoneal equilibration of protein-associated pentosidine is shown in the bottom of Fig. 2. In contrast to furosine, no difference is found between diabetic (solid black bars) and nondiabetic (stippled bars) subjects with respect to plasma or dialysate levels of pentosidine. At time 0 , in contrast to the furosine data which demonstrated equilibrium between glycated plasma proteins and glycated peritoneal proteins, there is a highly significant difference between the pentosidine content of plasma and peritoneal proteins. Over the time of intraperitoneal incubation, the pentosidine content of peritoneal proteins shows only a minor nonsignificant increase beyond the levels found at time 0 .

We modeled the kinetics of modification of peritoneal proteins which may occur in PD by in vitro incubations of proteins (obtained from the serum of a healthy individual and from an aliquot of spent peritoneal dialysate pooled from the 10-h dwell of 20 patients) with fresh $2.5 \%$ Dianeal ${ }^{\circledR}$ for periods equivalent to the $10 \mathrm{~h}$ peritoneal equilibration test. Incubations in the presence of $2.5 \%$ Dianeal ${ }^{\circledR}$ resulted in increases in protein glycation as measured by the furosine assay, Fig. 3, top. In addition, the rate of glycation of peritoneal proteins is greater than that of proteins from normal serum (top). By contrast, the pentosidine levels in healthy serum and in proteins

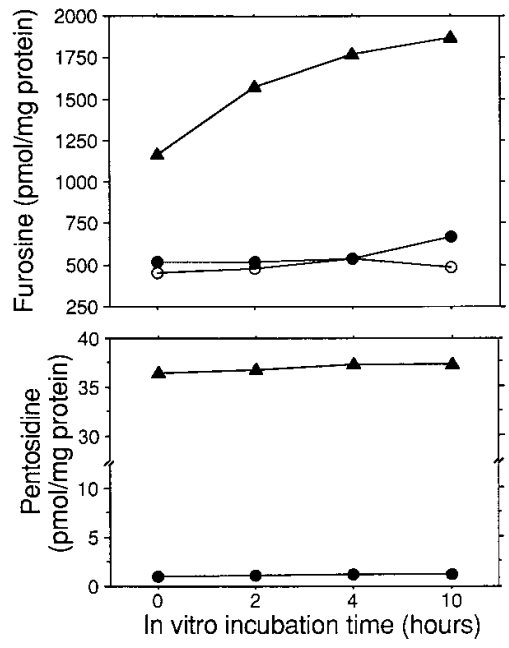

Table I. Normal Plasma and Peritoneal Fluid Protein Content of Pentosidine and Furosine*

\begin{tabular}{lccc}
\hline & Protein & Pentosidine & Furosine \\
\hline mg/ml & pmol/mg protein & pmol/mg protein \\
Plasma & $66.0 \pm 16$ & $1.29 \pm 0.58$ & $1010 \pm 166$ \\
Peritoneal Fluid & $32.2 \pm 7^{\ddagger}$ & $7.71 \pm 2.78^{\ddagger}$ & $1227 \pm 214^{\S}$
\end{tabular}

* Values expressed as means $\pm \mathrm{SD} ;{ }^{\ddagger} P<0.0001$ compared to plasma; ${ }^{\S} P<$ 0.05 compared to plasma.

from pooled peritoneal dialysate remained unchanged with incubation in $2.5 \%$ Dianeal $^{\circledR}$, Fig. 3, bottom. Thus, pentosidine formation rate in vitro is very slow, a finding which is important for the subsequent interpretation of the in vivo glycation data.

The in vivo data emphasize the greater pentosidine content of proteins in the peritoneal dialysate than the plasma, $\sim 20$ $\mathrm{pmol} / \mathrm{mg}$ at time 0 . Therefore we looked for evidence of the
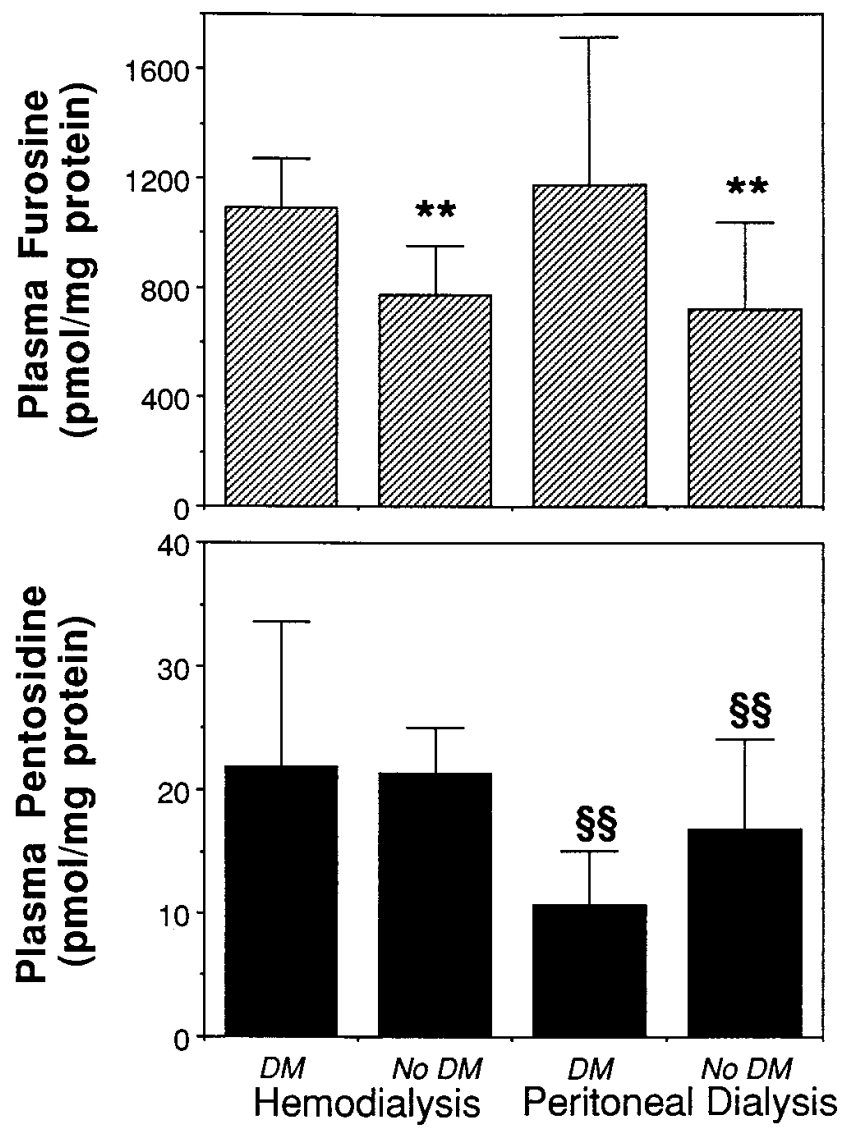

Figure 4. Effect of diabetes on plasma protein furosine and pentosidine content. Plasma levels of furosine and pentosidine in patients with and without diabetes mellitus treated with HD and PD. In top, $* * P<0.005$ comparing plasma furosine levels in patients with diabetes to levels in nondiabetic patients treated with either HD or PD. There are no significant differences in furosine with respect to dialysis modality. In bottom, $* * P<0.005$ comparing plasma pentosidine levels in PD patients with HD patients for the same diabetic status. There are no significant differences in pentosidine levels with respect to diabetic status. 


\section{Hemodialysis}
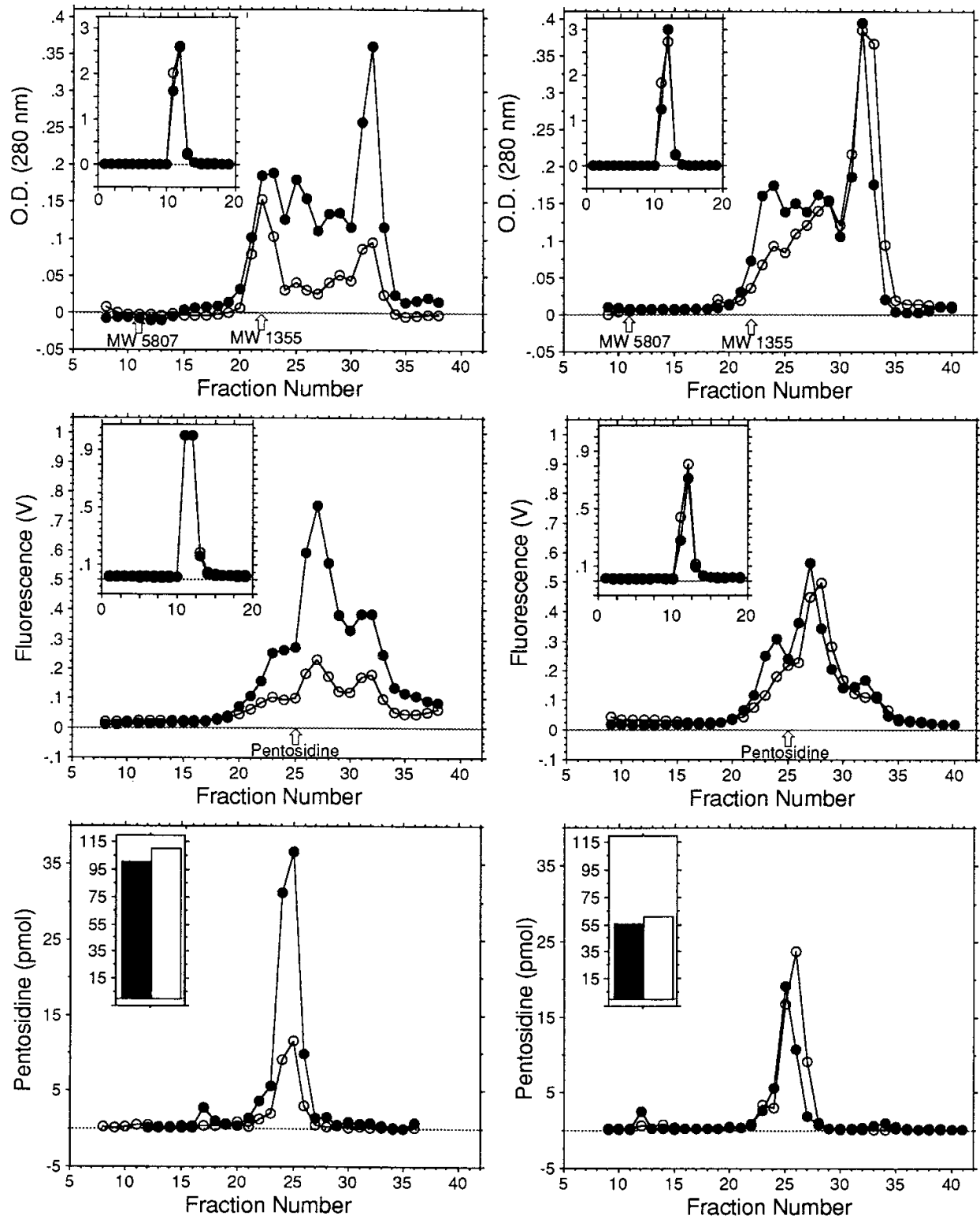

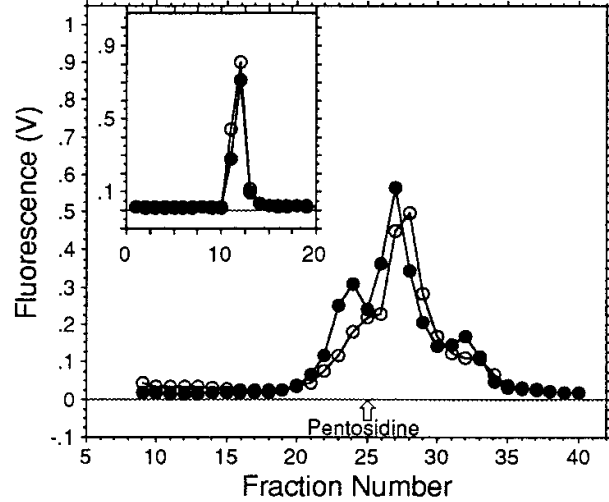

\section{Peritoneal Dialysis}

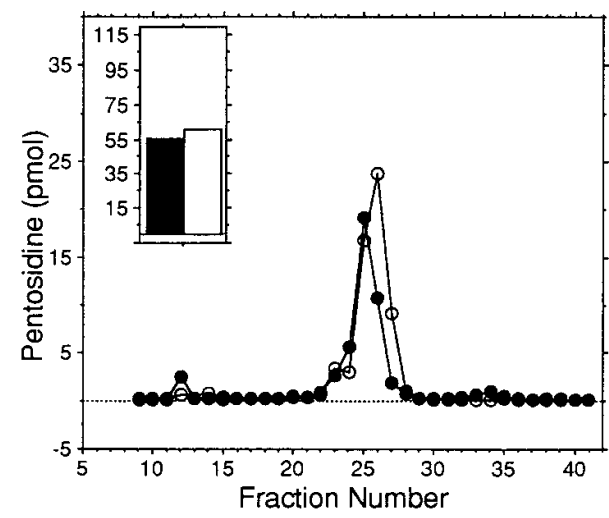

Figure 5. Gel filtration of serum from patients treated by hemodialysis or peritoneal dialysis. A pool of the low molecular weight fractions $(<10,000)$ from six serum samples of subjects treated by hemodialysis (left column) or peritoneal dialysis (right column) before (black circles) and after (open circles) treatment or exchange was subjected to column chromatography using a Bio-Gel P6 column. Fractions were measured for absorbance at $289 \mathrm{~nm}$ (top row), fluorescence (excitation $335 \mathrm{~nm}$, emission $385 \mathrm{~nm}$ ) (second row), or pentosidine (pmol per $3 \mathrm{ml}$ fraction) (bottom row). Calibration standards: myoglobin (17K), insulin $(5,807.6 \mathrm{~mol} \mathrm{wt})$, and vitamin B12 (1,355 mol wt). The fraction containing free pentosidine standard (mol wt 379) was identified as a fluorescence peak. The insets show the results of column chromatography of whole serum using a Bio-Gel P30 column. Individual fractions with a mol wt $>40 \mathrm{~K}$ are shown and are pooled for pentosidine. Note the difference in scales for ultraviolet and pentosidine measurements. presence of a plasma to peritoneal gradient for protein with a high pentosidine content in subjects without renal failure. The pentosidine and furosine content of proteins obtained from the peritoneal fluid of nine women with normal renal function is compared with their plasma protein content in Table I. The aspirated fluid has a lower protein content than plasma, but the protein has a markedly elevated pentosidine content and significantly elevated levels of furosine. These observations lend further strength to the idea that a mechanism may exist which results in the selective intraperitoneal segregation of proteins with higher AGE content than serum.

To compare the effects of HD and PD on the clearance of AGEs, we measured plasma levels of glycated and pentosidine-rich proteins in patients undergoing HD and PD. We found that the extent of plasma protein glycation is identical in both groups, being primarily dictated by the presence of diabetes (top, Fig. 4). In contrast, the pentosidine content of plasma proteins is substantially lower in patients on PD regardless of the presence of diabetes (bottom, Fig. 4). To determine which fractions of circulating glycated proteins are affected by dialysis, we performed gel filtration of serum samples obtained before and after dialysis. The insets in Fig. 5 demonstrate no difference between HD or PD before (solid circles) and after (open circles) dialysis with respect to the ultraviolet or fluorescence signals from the $>40 \mathrm{~K}$ fractions. In contrast, the pentosidine content of the high molecular weight fraction increased in serum from both HD and PD, reflecting the known effect of dialysis to induce hemoconcentration. HD but not PD is seen to decrease the fluorescence of fractions in the mol wt range 5,000-17,000. Fig. 5 demonstrates pre and postdialysis serum ultrafiltrates $<10,000 \mathrm{~mol}$ wt pooled from six patients on HD and six on PD. HD induces a more dramatic decrease in the $\mathrm{OD}$, fluorescence, and pentosidine signals in the mol wt range $<2,000$ than does PD. However the predialysis peak fluores- 


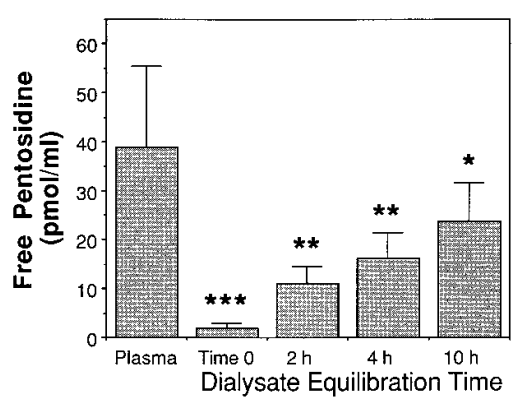

cence and pentosidine signals are greater in HD than in PD. This figure presents visual evidence that fluorescence and pentosidine signals are at "steady state" for patients treated with PD, whereas patients on HD experience higher predialysis peak levels and lower postdialysis trough levels.

In contrast to plasma proteins with a high pentosidine content, free pentosidine was detected in plasma of patients treated both by HD and PD. Fig. 6 shows that free pentosidine (mol wt 379) accumulates in the peritoneal fluid with a kinetic pattern similar to other solutes close to its size, dialysate levels approaching equilibrium with plasma. Fig. 7 represents the measurement of free pentosidine before and after dialysis in each of the six patients on HD and six on PD. A marked decrease in free pentosidine levels from patients on HD (black squares $)$ is noted from $105.2 \pm 37.9$ to $53.6 \pm 30.7 \mathrm{pmol} / \mathrm{ml}(P<$ 0.05), whereas levels in patients on PD (open triangles) make no significant change, from $63.9 \pm 31$ to $60.3 \pm 29.3 \mathrm{pmol} / \mathrm{ml}$.

We delineated the pentosidine content of fractions of pooled spent peritoneal dialysate of various molecular weights, separated by gel filtration. Table II summarizes these results, expressed as picomoles of pentosidine per milliliter of sample. The table also provides a comparison of spent dialysate with serum from patients on PD and HD. Gel filtration of serum obtained before a PD exchange or HD demonstrates that fractions $>10,000 \mathrm{~mol} w \mathrm{w}$ include free pentosidine, as well as pentosidine bound to small proteins. Free pentosidine represents $\sim 3-4 \%$ of the total circulating pentosidine for both patients on $\mathrm{PD}$ and HD, whereas pentosidine bound to small proteins alone is $\sim 1 \%$. The protein content of the pooled spent peritoneal dialysate is $0.9 \mathrm{mg} / \mathrm{ml}$ (80-fold less than plasma). In spent dialysate, $49 \%$ of the pentosidine is present on proteins $>10,000 \mathrm{~mol} \mathrm{wt}, 51 \%$ on proteins $<10,000 \mathrm{~mol} \mathrm{wt}$ of which $52 \%$ is free pentosidine ( $27 \%$ of the total).

Table III summarizes clearances, dialysate/plasma ratios and MTACs at $4 \mathrm{~h}$ of incubation for protein containing pento-

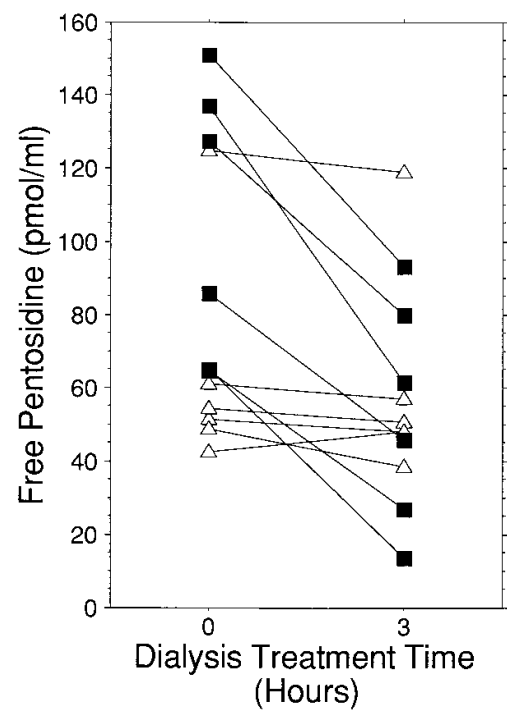

Figure 7. Effect of dialysis on plasma free pentosidine levels. Plasma levels of free pentosidine before and after hemodialysis (black squares) and before and at $3 \mathrm{~h}$ after a peritoneal dialysis exchange (open triangles). Predialysis HD levels are greater than the steady state PD levels $(P<0.05)$, but there is no difference in the postdialysis (postexchange) values between HD and PD. sidine or furosine and for free pentosidine, compared with urea, creatinine, $\beta-2$ microglobulin, and total protein. High $\mathrm{D} / \mathrm{P}$ ratios for protein containing pentosidine and furosine suggest either intraperitoneal formation or active transport of both Amadori product and AGE across the peritoneum (furosine and pentosidine). MTAC cannot be calculated for protein-bound pentosidine because plasma values are lower than peritoneal values at every time point. The MTAC for proteinassociated furosine is similar to urea, suggesting a large peritoneal surface area on which these nonenzymatic chemical reactions may take place. Calculated clearances of protein containing furosine and pentosidine are 30-300 $\times$ higher than the clearances of $\beta-2$ microglobulin or total protein, and $3-5 \times$ higher than the clearances of urea and creatinine. In contrast, the peritoneal clearance of free pentosidine is similar to creatinine, providing evidence that free pentosidine enters the peritoneal cavity by simple diffusion.

\section{Discussion}

The purpose of this study was to take advantage of the unique intraperitoneal hyperglycemic state which results from performing peritoneal dialysis to study the kinetics of in vivo protein glycation. Our data show that the plasma level of furosine is dependent on diabetic status for both patients on PD and on HD. In contrast we demonstrate no relationship between diabetic status and plasma pentosidine levels. Similarly, in vitro incubation data demonstrates increases in furosine but not pentosidine content of albumin or plasma proteins within the time frame of the peritoneal equilibration test.

Table II. Distribution of Pentosidine in High and Low Molecular Weight Fractions of Plasma and Peritoneal Dialysate

\begin{tabular}{|c|c|c|c|c|}
\hline & Protein content & $>10,000 \mathrm{~mol} \mathrm{wt}$ & $\begin{array}{c}<10,000 \mathrm{~mol} \mathrm{wt} \\
\text { excluding free } \\
\text { pentosidine }\end{array}$ & $\begin{array}{l}\text { Free pentosidine } \\
\quad(\text { mol wt } 379)\end{array}$ \\
\hline & $m g / m l$ & pmol per $\mathrm{ml} / \%$ protein & pmol per $m l / \%$ protein & pmol per $m l / \%$ protein \\
\hline Hemodialysis Serum & 81.3 & $2,085 / 95.4 \%$ & $21 / 0.9 \%$ & $79 / 3.6 \%$ \\
\hline Peritoneal Dialysis Serum & 70.0 & $1,387 / 96.4 \%$ & $14 / 0.9 \%$ & $38 / 2.6 \%$ \\
\hline Pooled Spent Peritoneal Dialysate & 0.9 & $28 / 50 \%$ & $13 / 23.2 \%$ & $15 / 26.8 \%$ \\
\hline
\end{tabular}


Table III. Clearances and Mass Transfer Area Coefficients*

\begin{tabular}{lccc}
\hline & Clearance & Dialysate/plasma & MTAC \\
\hline & $\mu l / m i n$ & & \\
Urea & $8,698 \pm 1,772$ & $0.89 \pm 0.11$ & $24.2 \pm 9.9$ \\
Creatinine & $6,284 \pm 1,294$ & $0.65 \pm 0.12$ & $10.7 \pm 3.5$ \\
$\beta-2$ microglobulin & $1,115 \pm 643$ & $0.12 \pm 0.08$ & $1.2 \pm 0.8$ \\
Total protein & $94.2 \pm 58.4$ & $0.01 \pm 0.006$ & $0.095 \pm 0.06$ \\
Free pentosidine & $3,950 \pm 2,101$ & $0.4 \pm 0.2$ & $5.5 \pm 3.5$ \\
Protein-bound pentosidine & $28.6 \pm 14.7^{\ddagger \S}$ & $3.0 \pm 1.8$ & $\|$ \\
Protein-bound furosine & $24.5 \pm 23.0^{\ddagger \S}$ & $2.4 \pm 2.1$ & $24.1 \pm 16.4^{\S}$ \\
& & &
\end{tabular}

*Values expressed as means $\pm \mathrm{SD} ;{ }^{\ddagger} \mathrm{ml} /$ minute; ${ }^{\S}$ apparent clearance or MTAC includes rate of intraperitoneal formation; " cannot be evaluated because plasma values lower than peritoneal values at all time points.

Albumin present in the peritoneal space most likely originates from plasma. The progressive increase in albumin concentration with time is in part a response to an osmotic effect of hypertonic glucose dialysate. In situ glycation of amino acids present on proteins most likely contributes to the rising peritoneal protein furosine content measured with increasing dialysate incubation time. In addition our calculation of the clearance and MTAC for furosine suggests a plasma-peritoneal equilibrium for glycated proteins. The complex differences between the patterns of furosine equilibration and formation in patients with and without diabetes suggests that glycated proteins are formed in both plasma and peritoneum, and also move from plasma into the peritoneal space.

We have previously demonstrated that the pentosidine content of peritoneal biopsy tissue from patients on PD is significantly elevated compared to peritoneal biopsy tissue from patients on HD (7). We believe that high tissue pentosidine levels reflect many months of intraperitoneal exposure to glucose dialysate. Paradoxically, plasma protein pentosidine levels are much lower in patients on PD than in those on HD. The calculated clearances of protein-bound pentosidine and furosine are also much greater than $\beta-2$ microglobulin and total protein. A mechanism to explain the difference between the pentosidine content of peritoneal and plasma proteins remains to be determined. Possibilities include increased permeability due to glycation of the peritoneal membrane, by mechanisms similar to those seen in other glycated basement membranes (14). Alternatively highly glycosylated peritoneal tissue might continuously shed pentosidine-rich cellular proteins into the dialysate. This hypothesis is supported by a recent demonstration by Giardino et al. that AGEs form more rapidly intracellularly than in the circulation (15).

The observation that plasma pentosidine levels are lower in patients on PD than those on HD may also be explained by the known difference in albumin kinetics between these two groups of patients (16). Patients on PD experience a higher net loss of total proteins and albumin across the peritoneal membrane. Increased hepatic synthesis of albumin in response to this loss may contribute to a pool of "younger," less glycated albumin in the circulation of patients on PD compared with HD. However the finding in women with normal renal function of an increased peritoneal/plasma ratio of pentosidinerich proteins suggests that proteins with a high pentosidine content may be actively transported across the peritoneum.
Thus it is also possible that proteins modified by the Maillard reaction are selectively transported from the plasma into the peritoneum. Evidence for active transmembrane transport has been previously documented across the glomerulus for both the Amadori product (17) and AGEs (18-20).

In general quantitatively more low molecular weight than high molecular weight proteins are lost into the peritoneal dialysate during PD (21). Korbet et al. have reported peritoneal dialysate levels for low molecular weight AGE peptides measured by ELISA (13). Using the AGE-ELISA, dialysate/ plasma $(\mathrm{D} / \mathrm{P})$ ratios and MTAC were found to be quite comparable to values obtained for inulin, mol wt 5,000. An eventual equilibrium between dialysate and plasma levels of AGEs was attained. Our kinetics data demonstrate a similar equilibrium between dialysate and plasma for furosine at the $10-\mathrm{h}$ time period. However we also provide evidence for in situ glycation. The speed of in vitro glycation does not completely account for the magnitude of the in vivo increase in glycation. Thus a comparison of the in vivo and in vitro kinetic data for furosine provides additional strength to the hypothesis that glycated proteins enter the peritoneum at a rate faster than can be explained by the combination of diffusion and in vitro formation.

High circulating levels of AGEs which correlate positively with elevated creatinine levels have been described in renal failure patients when measured both by ELISA $(13,22,23)$ and by the biochemical methods described in this paper $(1,7)$. The estimated molecular weight of AGEs measured by Makita's ELISA is between 2,200 and 6,000 $(15,22)$ and by Papanastasiou's assay between 1,500 and 2,000 (24). Vlassara has used the term "AGE-peptides" to describe AGEs of these molecular weights (25). Unlike protein-bound pentosidine (7), AGE-peptides can be removed from plasma in small amounts by hemodialysis (22). For these reasons we compared the effectiveness of HD and PD on the clearance of AGEs from serum by measuring the pentosidine content of fractions of various molecular weights obtained by gel filtration.

Whereas neither HD nor PD causes a significant change in the levels of pentosidine bound to high molecular weight proteins $(>40,000 \mathrm{~mol} w \mathrm{t})$, both $\mathrm{HD}$ and PD result in removal of pentosidine associated with proteins of $<10,000$ mol wt. Fig. 5 demonstrates a steady state for serum pentosidine fractions in PD. In contrast HD induces a marked decrease in ultraviolet and fluorescence signals and a threefold decrease in the pentosidine content of the fractions. In addition the predialysis samples from patients treated by HD show peak fluorescence which is $2 \times$ and pentosidine which is $1.5 \times$ that found in patients treated by PD. The magnitude of these relationships is quite similar to previous reports comparing levels of low molecular weight AGEs by ELISA in patients on PD and before and after HD (23). Circulating low molecular weight AGE fractions and, by implication, free pentosidine derive from breakdown of AGEs on tissue or on high molecular weight proteins (23). Direct reactivity of these break-down products has been demonstrated in vitro and in vivo (23). Therefore the accumulation of AGE fragments in patients with renal failure may mediate many uremic toxic effects.

In summary our kinetics data provide both in vivo and in vitro evidence for the formation of glycated proteins (furosine) in the peritoneal cavity during the time course of a routine peritoneal equilibration test. We show a consistently elevated content of pentosidine in proteins within the peritoneal cavity 
but no in vitro evidence for the formation of pentosidine during the period of observation. Peritoneal dialysate also contains free pentosidine and fluorescent low molecular weight products which are cleared from the blood by diffusion. Therefore PD, using glucose-based dialysate, is associated with the intraperitoneal formation, accumulation, and clearance of AGEs. In addition the patterns of clearance of serum fractions containing pentosidine differ markedly between PD and HD. Circulating levels of protein-bound and free pentosidine are lower in patients treated by PD than in those treated by HD. The two major treatment modalities for end stage renal failure differ with respect to clearance of AGEs and its breakdown products. The long-term systemic consequences of these complex differences between therapies remain to be determined.

\section{Acknowledgments}

We thank the nurses in the Peritoneal Dialysis Unit at University Hospitals (Ms. Lynda Newman, RN, MSN, CNS, CNN; Ms. Maureen Tessman, RN, CNN; Ms. Theresa Hanslik, RN, CNN, and Ms. Kathleen Ferrara, RN, CNN) for performing the peritoneal equilibration tests, and Mr. John Fogarty for assistance with selected experiments.

Supported by a grant from the Extramural Grant Program, Baxter Corporation (McGaw Park, IL) and grants from the National Institute of Diabetes and Digestive and Kidney Diseases DK45619-01 (to M.A. Friedlander) and from the National Institute on Ageing AG 05601 (to V.M. Monnier).

\section{References}

1. Sell, D.R., and V.M. Monnier. 1990. End stage renal disease and diabetes catalyze the formation of a pentose-derived crosslink from aging human collagen. J. Clin. Invest. 85:380-384.

2. Vlassara, H., R. Bucala, and L. Striker. 1994. Pathogenic effects of advanced glycosylation: biochemical, biological, and clinical implications for diabetes and aging. J. Lab. Invest. 70:138-151.

3. Sell, D.R., and V.M. Monnier. 1989. Structural elucidation of a fluorescent cross link from human senescent extracellular matrix: implication of pentoses in the aging process. J. Biol. Chem. 264:21597-21602.

4. McCance, D.R., D.G. Dyer, J.A. Dunn, K.E. Bailie, S.R. Thorpe, J.W. Baynes, and T.J. Lyons. 1993. Maillard reaction products and their relation to complications in insulin-dependent diabetes mellitus. J. Clin. Invest. 91:24702478.

5. Beisswenger, P.J., L.L. Moore, T. Brinck-Johnson, and T.J. Curphey. 1993. Increased collagen-linked pentosidine levels and advanced glycosylation end products in early diabetic nephropathy. J. Clin. Invest. 92:212-217.

6. Hricik, D.E., J.A. Schulak, D.R. Sell, J.F. Fogarty, and V.M. Monnier. 1993. Effects of kidney or kidney-pancreas transplantation on plasma pentosidine. Kidney Int. 43:398-403.

7. Friedlander, M.A., Y.C. Wu, J.A. Schulak, V.M. Monnier, and D.A.
Hricik. 1995. Influence of dialysis modality on plasma and tissue concentrations of pentosidine in patients with end-stage renal disease. Am. J. Kidney Dis. 25: $441-451$.

8. Wu, Y.C., V. Monnier, and M. Friedlander. 1995. Reliable determination of furosine in human serum and dialysate proteins by high-performance liquid chromatography. J. Chromatogr. B. Biomed. Appl. 667:328-332.

9. Takahashi, M., T. Ohishi, H. Aoshima, K. Kawana, K. Kushid, T. Inoue, and K. Horiuchi. 1993. The Maillard protein cross-link pentosidine in urine from diabetic patients. Diabetologia. 36:664-667.

10. Takahashi, M., K. Kushida, K. Kawana, C. Ishihara, M. Denda, T. Inoue, and K. Horiuchi. 1993. Quantification of the cross-link pentosidine in serum from normal and uremic subjects. Clin. Chem. 39:2162-2165.

11. Odetti, P., J. Fogarty, D.R. Sell, and V.M. Monnier. 1992. Chromatographic quantitation of plasma and erythrocyte pentosidine in diabetic and uremic subjects. Diabetes. 41:153-159.

12. Resmini, P., L. Pelligrino, and G. Batelli. 1990. Accurate quantification of furosine in milk and dairy products by a direct HPLC method. Ital. J. Food Sci. 3:173-183.

13. Korbet, S.M., Z. Makita, C.A. Firanek, and H. Vlassara. 1993. Advanced glycosylation end products in CAPD patients. Am. J. Kid. Dis 22:588591.

14. Anderson, S.S., E.C. Tsilibary, and A.S. Charonis. 1993. Nonenzymatic glycation induced modifications of intact bovine kidney tubular basement membrane. J. Clin. Invest. 92:3045-3052.

15. Giardino, I., D. Edelstein, and M. Brownlee. 1994. Nonenzymatic glycosylation in vitro and in bovine endothelial cells alters basic fibroblast growth factor activity. A model for intracellular glycosylation in diabetes. J. Clin. Invest. $94: 110-117$.

16. Kaysen, G.A., and P. Schoenfeld. 1984. Albumin homeostasis in patients undergoing continuous ambulatory peritoneal dialysis. Kidney Int. 25: 107-114.

17. Cohen, M.P., E. Hud, and V.Y. Wu. 1994. Amelioration of diabetic nephropathy by treatment with monoclonal antibodies against glycated albumin. Kidney Int. 45:1673-1679.

18. Williams, S.K., J.J. Devenny, and M.W. Bitensky. 1981. Micropinocytotic ingestion of glycosylated albumin by isolated microvessels: possible role in the pathogenesis of diabetic microangiopathy. Proc. Natl. Acad. Sci. USA. 78 : 2393-2397.

19. Williams, S.K., and N.J. Solenski. 1984. Enhanced vesicular ingestion of nonenzymatically glycosylated proteins by capillary endothelium. Microvasc. Res. 28:311-321.

20. Williams, S.K., and R.K. Siegal. 1985. Preferential transport of nonenzymatically glycosylated ferritin across the kidney glomerulus. Kidney Int. 28:146152

21. Dulaney, J.T., and F.E. Hatch. 1984. Peritoneal dialysis and loss of proteins: a review. Kidney Int. 26:253-262.

22. Makita, Z., S. Radoff, E.J. Rayfield, Z. Yang, E. Skolnik, V. Delaney, E.A. Friedman, A. Cerami, and H. Vlassara. 1991. Advanced glycosylation end products in patients with diabetic nephropathy. N. Engl. J. Med. 325:836-842.

23. Makita, Z., R. Bucala, E.J. Rayfield, E.A. Friedman, A.M. Kaufman, S.M. Korbet, R.H. Barth, J.A. Winston, H. Fuh, K.R. Manogue, et al. 1994. Reactive glycosylation end products in diabetic uremia and treatment of renal failure. Lancet. 343:1519-1522.

24. Papanastasiou, P., L. Grass, H. Rodela, A. Patrikarea, D. Oreopoulos, and E.P. Diamandis. 1994. Immunological quantification of advanced glycosylation end-products in the serum of patients on hemodialysis or CAPD. Kidney Int. 46:216-222.

25. Vlassara, H. 1994. Serum advanced glycosylation end products: a new class of uremic toxins? Blood Purif. 12:54-59. 